Article

\title{
How the Architecture of Housing Blocks Amplifies or Dampens Interethnic Tensions in Ethnically Diverse Neighbourhoods
}

\author{
Maurice Crul $^{1, *}$, Carl H. D. Steinmetz ${ }^{2}$ and Frans Lelie ${ }^{1}$ \\ ${ }^{1}$ Department of Sociology, Vrije Universiteit Amsterdam, 1081 HV Amsterdam, The Netherlands; E-Mails: m.r.j.crul@vu.nl \\ (M.C.), f.lelie@vu.nl (F.L.) \\ 2 Expats \& Immigrants Amsterdam B.V., 1019 LL Amsterdam, The Netherlands; E-Mail: carl@expats-immigrants.com \\ * Corresponding author
}

Submitted: 23 March 2019 | Accepted: 13 February 2020 | Published: 20 March 2020

\begin{abstract}
This article explores how the architecture of neighbourhoods influences interethnic tensions in ethnically diverse neighbourhoods. We found that people of Dutch descent living in apartments in four storey walk-ups in ethnically diverse innercity neighbourhoods seem less likely to feel threatened by ethnic diversity than people living in in similarly diverse suburbs characterized by larger housing blocks featuring inner courtyards and galleries. Further analysis reveals that the residents of these suburbs share various types of semi-public spaces and have competing interests in using them, whereas the residents of inner-city neighbourhoods share fewer semi-public spaces and therefore have more scope to choose when and how to engage in interethnic contact with other residents. We also explore residents' housing histories and examine differences between people who either have more negative or more positive views on diversity with regard to their active participation in various organizations. This last piece of the puzzle will be used to analyse the potential for both negative and positive messages about ethnic diversity to spread. Based on the empirical findings, we will formulate some building blocks that can help to further explain the level of perceived ethnic tensions in ethnically diverse neighbourhoods.
\end{abstract}

\section{Keywords}

diversity; ethnic tensions; housing; interethnic contact; neighbourhoods

\section{Issue}

This article is part of the issue "Institutions of Inclusion and Exclusion" edited by J. Cok Vrooman (Utrecht University, The Netherlands/The Netherlands Institute for Social Research|SCP, The Netherlands) and Marcel Coenders (Utrecht University, The Netherlands/The Netherlands Institute for Social Research|SCP, The Netherlands).

(C) 2020 by the authors; licensee Cogitatio (Lisbon, Portugal). This article is licensed under a Creative Commons Attribution 4.0 International License (CC BY).

\section{Introduction}

Little research has been done so far in the Netherlands into why ethnic tensions in diverse neighbourhoods occur or, equally as interesting, why they do not materialize. This article examines this topic by analysing the possible influence of the physical environment in neighbourhoods through the following research question: How does the architecture of housing blocks and neighbourhoods amplify or dampen ethnic tensions in ethnically diverse neighbourhoods? Most research on interethnic contact and possible positive or negative outcomes has focussed on human conditions, such as the duration or intensity of the contact or differences in group characteristics (such as differences in socio-economic status). In this article we will explore the influence exerted by the physical environment in which contact occurs, by focusing on the types of housing in which residents interact daily.

We will use survey data from two research projects carried out in Amsterdam that allow us to distinguish between types of housing and obtain detailed information about the interaction between residents in these housing types. We will start out by exploring whether architectural differences are related to specific reactions 
among people living in ethnically diverse settings. The data presents differences in outcomes for two types of housing: inner-city apartments in four storey walk-ups in ethnically diverse working-class neighbourhoods, versus suburban apartments in housing blocks in ethnically diverse working-class neighbourhoods. In the second part of the article we take a closer look at how these differences can be explained. For this we use data obtained from the city council for two Amsterdam neighbourhoods, one of which typically features inner-city apartments, the other consisting of suburban housing blocks. We selected these particular neighbourhoods because although their ethnic composition is almost identical, they have the most polarized outcomes in Amsterdam in terms of social cohesion and ethnic tensions. We also explore residents' housing histories and examine differences concerning active participation in various organizations between people who either have more negative or more positive views on diversity. We will use this last piece of the puzzle to analyse the potential for negative and positive messages about ethnic diversity to spread. Based on the empirical findings of these two studies, we will propose elements that can help further the explanation of ethnic tensions in diverse neighbourhoods.

\section{Theoretical Framework: Going Beyond the Interethnic Contact Hypothesis}

In its early stages, research on ethnic tensions largely focussed on studying processes of decolonization. Horowitz published his seminal text "Ethnic Groups in Conflict" in 1985. Twenty years later Brubaker and Laitan (2004) argued that there is still a lack of clarity regarding what should be considered as ethnic conflict and what causes it. Since then, the number of articles has increased considerably and researchers from an array of disciplinary backgrounds, ranging from political science to social psychology and anthropology, have studied ethnic conflict and its causes. This article limits itself to interethnic tensions involving daily encounters in ethnically diverse neighbourhoods.

Allport was one of the first to extensively study interethnic contact and conflict. He developed the intergroup contact hypothesis in 1954, based on his research among Second World War soldiers in integrated platoons in the US army (Allport, 1954). Since then many researchers have both worked with and challenged the hypothesis that close interethnic contact will bridge prejudices and conflicts (see, for example, Amir, 1976; Árnadóttir, Lolliot, Brown, \& Hewstone, 2018; Barlow et al., 2012; Brewer \& Kramer, 1985; Paolini et al., 2014; Rothbart \& John, 1985; Wright, Aron, Mc Laughlin-Volpe, \& Ropp, 1997). Pettigrew and Tropp (2006) conducted one of the most comprehensive meta-studies on this topic. They analysed the results of 515 studies on intergroup contact and concluded that contact typically reduces intergroup prejudices. The results of the metaanalysis were controlled for by different age groups, ge- ographical areas and contact settings. In reference to Allport's work, Pettigrew has always emphasized that certain conditions (equal status, common goals, intergroup cooperation and support of social institutions) must be in place for positive contact effects to occur (Pettigrew, 1998). Both Allport and Pettigrew warned us that competition or unequal status can fuel animosity between groups. Increased anxiety and threat can further enhance conflicts between groups (see Tropp, 2016). Based on the empirical findings in this article, we will explore a different path than the founders of intergroup contact theory. Instead of examining under which human conditions (e.g., differences in group characteristics, unequal status and power relations) interethnic contact can lead to positive attitudes, we will analyse which physical conditions in a neighbourhood context are related to either negative or positive attitudes.

\section{The Influence of Architecture on Attitudes towards Diversity}

We will first analyse whether different types of housing and architecture in semi-public spaces are related to different attitudes towards living in ethnically diverse settings, making use of a survey conducted in highly diverse neighbourhoods in Amsterdam. As part of a large-scale international survey, the Integration of the European Second Generation (TIES), the Dutch TIES survey was used to analyse the position of the Turkish and Moroccan second generation and a comparison group of people of Dutch descent in Amsterdam. For this purpose, respondents were sampled from the municipal register. The survey was conducted among 750 people between 18 and 35 years of age. Data from the register was used to draw a representative sample of second-generation Turkish and Moroccan respondents according to their actual presence in these neighbourhoods (for details about the sample design see Groenewold, 2008). This meant in practice that respondents were mainly sampled in neighbourhoods with a high percentage of migrants (many of them majority-minority neighbourhoods). On average, people of Turkish and Moroccan descent live in the poorest neighbourhoods (Crul \& Heering, 2008). Despite the survey being ten years old, it is still one of the best data sets for studying the issues we are addressing here, because TIES also sampled a comparison group of people of Dutch descent of the same age living in these same neighbourhoods. The definition used to determine whether a person is of Dutch descent is that used by Statistics Netherlands (2020), the national statistical bureau, and is as follows: "A person born in the Netherlands, both of whose parents were also born in the Netherlands." The way the sample is drawn makes TIES the ideal survey for studying the reactions of people of Dutch descent to living in highly diverse settings.

The 23 Amsterdam neighbourhoods in which the survey was conducted are either working-class inner-city neighbourhoods where labour migrants settled in the 
1960s and 1970s or working-class suburbs where migrant families moved to in the 1980s due to the availability of affordable larger houses and more green areas for children. Consequently, the average socio-economic status of people living in both types of neighbourhoods was very similar. In both cases, most of the housing was subsidized social housing.

The TIES survey contains several questions on housing and also collected data on the respondents' neighbourhoods. For the purpose of this article we conducted an explorative analysis to see which neighbourhood and housing characteristics were relevant in relation to residents' reactions to ethnic diversity. The best predictor for differences in attitudes towards ethnic diversity is a question in the TIES survey asking respondents if they think that living alongside people of a different ethnic background is either an enrichment or a threat to their own way of living. It is a five-point scale question in which the midpoint gives respondents the opportunity to say that it makes no difference.

We divided the residents into four groups corresponding with four types of housing we detected, based on the neighbourhoods they lived in and the number of floors in their buildings or housing blocks: (1) four storey street level apartments in inner-city working-class neighbourhoods; (2) four storey apartment blocks in workingclass suburban neighbourhoods; (3) low-rise apartment blocks in working-class suburban neighbourhoods; and (4) high-rise (more than four-storeys) apartment blocks in working-class suburban neighbourhoods.

There were no significant differences between respondents living in the three types of suburban housing in terms of how they perceived living in an ethnically diverse environment. But we did find significant results when we placed them in juxtaposition with inner-city respondents. Generally, the people of Dutch descent in the TIES neighbourhoods do not feel threatened by living in a diverse setting. However, as we can see in Table 1, double the number of respondents living in suburban neighbourhoods stated that they felt threatened, compared to their peers in inner-city neighbourhoods. The correlation is significant $(p<0.01)$.

We controlled for whether respondents in these two types of housing differed on any particular individual characteristics. They did not differ in terms of socioeconomic characteristics (five-point EGP coding scheme) or educational background characteristics. The majority of respondents (about three quarters) in both the innercity and the suburban neighbourhoods had only been living there for five years or less, which makes sense given their relatively young age (18 to 35 ).

The people living in four storey walk-ups in inner-city working-class neighbourhoods usually shared their building with three or four neighbours, and normally only the ground floor would have access to a small private back garden. Children usually played in the streets, small local squares or nearby parks. The people in the suburbs either lived in four storey housing blocks with about seven apartments organized around a porch, or in a high-rise building with between fifteen and twenty-five storeys and shared galleries. These types of suburban housing usually have green areas between the blocks where children can play, or inner courtyards enclosed within the buildings. In the next section we will take a closer look at the type of interethnic encounters that these architectural differences produce and how they relate to attitudes towards diversity.

A further relevant finding from the data analysis is that more than three times as many respondents from the suburbs had been raised in Amsterdam in comparison to the inner-city respondents ( $39 \%$ versus $12 \%$ ). The latter usually came from smaller cities (and thus less diverse neighbourhoods) throughout the Netherlands. Of those raised in Amsterdam, 58\% of the suburban residents were still living in the neighbourhood they had grown up in. Given the ethnic composition of these lower-class suburban neighbourhoods, this group has more pre-existing experiences of living in an ethnically diverse context. Of these people, 19\% stated it is (rather) threatening to live in an ethnically diverse setting, which is indeed a much higher percentage than among any other group. One may assume that interethnic contact when they were growing up in an increasingly diverse neighbourhood may have influenced their current attitudes. Naturally, we must be careful about drawing this conclusion as proper longitudinal data are needed to substantiate it, but qualitative research drawn upon in the next section also seems to point in this direction.

Table 1. People of Dutch descent (18 to 35 years of age) in ethnically diverse Amsterdam neighbourhoods. Survey question: "Do you think that living together with people of different ethnic origin is an enrichment or a threat to your own way of living?"

\begin{tabular}{|c|c|c|c|c|c|c|}
\hline & Threatening & $\begin{array}{l}\text { Rather } \\
\text { threatening }\end{array}$ & $\begin{array}{l}\text { Makes no } \\
\text { difference }\end{array}$ & $\begin{array}{c}\text { Rather } \\
\text { enriching }\end{array}$ & Enriching & Total $\mathrm{N}=232$ \\
\hline $\begin{array}{l}\text { Respondents in ethnically } \\
\text { diverse inner-city lower-class } \\
\text { neighbourhoods }\end{array}$ & $1 \%$ & $5 \%$ & $15 \%$ & $37 \%$ & $41 \%$ & $N=78$ \\
\hline $\begin{array}{l}\text { Respondents in ethnically } \\
\text { diverse suburban lower-class } \\
\text { neighbourhoods }\end{array}$ & $6 \%$ & $7 \%$ & $34 \%$ & $26 \%$ & $28 \%$ & $N=154$ \\
\hline
\end{tabular}

Source: TIES Survey (2008). 


\section{Amplifying or Dampening Interethnic Tensions: Neighbourhood Characteristics}

In this section we will try to dig deeper into neighbourhood and housing characteristics using another survey carried out in Amsterdam by the municipal statistical bureau, or OIS (Onderzoek, Informatie \& Statistiek), on interethnic tensions and conflicts in Amsterdam's neighbourhoods (Broekhuizen, van Marissing, \& Wonderen, 2012; Wonderen \& Broekhuizen, 2012). Of the twenty neighbourhoods studied, we looked at data published on two neighbourhoods that represent the two ideal types we distinguished in the previous section. The two neighbourhoods are at opposite ends of a scale measuring interethnic tensions between neighbourhood residents, making this the most extreme case comparison. By looking at the extremes we hope to gain insight into whether the architecture of these neighbourhoods in combination with the housing histories of the residents has the potential to either fuel or diminish tensions. The same research methodology was used for both neighbourhood studies (e.g., research design and format). The fact that their ethnic make-up was so similar provided yet another reason to choose these particular neighbourhoods for the comparison.

Before presenting the results, let us briefly describe the two neighbourhoods. The Jacob van Lennep neighbourhood, an inner-city working-class neighbourhood with a large stock of social housing, has relatively few interethnic tensions. Immigrants started moving into this neighbourhood in the 1970s. During this period, many people of Dutch descent who were uncomfortable with the neighbourhood's changing ethnic composition moved to satellite towns like Almere and Lelystad. From the 1990s until recently, when prices began to rocket, in a slow process of gentrification, young families of Dutch descent started moving to this neighbourhood because of the relatively cheap rents. Unlike the older inhabitants who had moved away, these newcomers were usually well aware of the neighbourhood's ethnic make-up before moving there, as it was known for being a typical 'immigrant neighbourhood.' According to the qualitative part of the research many newcomers even chose the neighbourhood for its ethnic mix.

The second neighbourhood, which has a lot of interethnic tension, is the Harbour Island West neighbourhood, a newly-built lower-class neighbourhood on the outskirts of Amsterdam with more privately-owned apartments than the Jacob van Lennep neighbourhood. The houses are often occupied by people of both immigrant and native Dutch descent who had previously lived in the increasingly expensive city centre, but also by newcomers to Amsterdam (both expats and people from other parts of the Netherlands). According to the qualitative part of the research, which included interviews with neighbourhood residents, some of the people in the Harbour Island West neighbourhood who expressed negative opinions about living in an ethnically diverse neighbourhood have been very vocal (both in neighbourhood or housing association meetings and in the media) and are major contributors to the negative atmosphere surrounding ethnic diversity in their neighbourhood (Broekhuizen et al., 2012). They are found among both people of Dutch descent and those of immigrant descent. The qualitative part of this study mentions that some of the people of Dutch descent had chosen to move to this new neighbourhood in the outskirts of Amsterdam because they had had negative experiences of living in an ethnically diverse inner-city neighbourhood. They had not, however, expected the newlybuilt neighbourhood to become equally multi-ethnic.

For the research 263 residents of 16 years and older were interviewed in the Harbour Island West neighbourhood, 155 of whom were of Dutch descent. The qualitative part of the research consisted of 51 in-depth interviews with residents and professionals. In the Jacob van Lennep neighbourhood 200 residents of sixteen years and older were interviewed, 120 of whom were of Dutch descent. Here, the qualitative part included 71 interviews with residents and professionals.

In both neighbourhoods, about half of the population is of Dutch descent. Both neighbourhoods accommodate established groups of immigrants and newcomers. In the Harbour Island West neighbourhood, almost half of the inhabitants are of Dutch descent $(47 \%)$. Of the immigrant groups, residents of Surinamese descent form the largest group (13\%) and those of Moroccan descent the second largest (10\%). The remaining quarter comes from a multitude of countries (Broekhuizen et al., 2012. p. 77). The population composition in the Jacob van Lennep neighbourhood is very similar to that of the Harbour Island West neighbourhood. About half of the population is of native Dutch descent (53\%). In the Jacob van Lennep neighbourhood people of Moroccan and Turkish descent form the largest migrant groups and the percentage of people of Surinamese descent is $6 \%$. This neighbourhood houses a larger group of recently arrived immigrants from Eastern European countries (Wonderen \& Broekhuizen, 2012, p. 87). Comparison of the socioeconomic composition of the neighbourhoods shows that the residents in the Jacob van Lennep neighbourhood are more often members of the working class than the Harbour Island West inhabitants. The Jacob van Lennep neighbourhood still has a relatively large native Dutch, working-class population as well as many Moroccan and Turkish low-income first-generation and one-and-a-half generation families. The Harbour Island West neighbourhood has more families belonging to the so-called second generation, who are often upwardly mobile (Crul \& Heering, 2008).

Ethnic tensions and conflicts differ substantially between the two neighbourhoods. The newly crafted Harbour Island West neighbourhood has by far the highest percentage of conflicts reported by residents and one of the lowest levels of trust of all twenty neighbourhoods studied in this city-wide research (Broekhuizen et al., 
2012, pp. 79-80). Almost half of the Harbour Island West respondents (47\%) reported "a lot of tension." A quarter $(24 \%)$ stated that there is "a lot of conflict between different ethnic groups" and $24 \%$ reported having "little or no trust" in their neighbours (Broekhuizen et al., 2012, pp. 79-80). The study also provides insights into how respondents interpret these conflicts. Almost half of the respondents (48\%) reporting tensions, stated that they are "caused by cultural differences between different ethnic groups" (Broekhuizen et al., 2012, pp. 79-80). More than a third of the respondents (38\%) attributed tensions to "differences in norms and values" (Broekhuizen et al., 2012 , p. 30). More than a third (37\%) of the respondents reported having "negative feelings about certain ethnic groups" (Broekhuizen et al., 2012, p. 28). In the Jacob van Lennep neighbourhood, however, no major tensions were reported. The number of conflicts in this neighbourhood was on the other end of the scale: Compared to the Harbour Island West neighbourhood, almost three times fewer respondents reported tensions (16\%) (Wonderen \& Broekhuizen, 2012, p. 26). This also applies to conflicts between ethnic groups, $12 \%$ according to Wonderen and Broekhuizen (2012, p. 27). At 14\%, the group that had little or no trust in their neighbours is also much smaller (Wonderen \& Broekhuizen, 2012, p. 33). Residents who did report conflicts, put them in a different perspective: In the Jacob van Lennep neighbourhood, only $26 \%$ of those reporting conflicts attributed them to cultural differences. Most respondents in this neighbourhood framed conflicts in terms of age and generation: according to them, youngsters have conflicts with adults (Wonderen \& Broekhuizen, 2012, p. 30).

The most important topic related to ethnic tensions mentioned by residents was youths "hanging out," loitering and being "a nuisance" to other residents in public or semi-public spaces such as corridors, staircases, or the pavement in front of the housing blocks or a nearby square (Broekhuizen et al., 2012; Wonderen \& Broekhuizen, 2012; see also Tersteeg \& Pinkster, 2016; van Marissing, 2014). The newly-built housing blocks in the New Harbour West neighbourhood have numerous shared semi-public spaces, such as an inner courtyard, shared corridors, lifts and a garage. Although the three or four storey walk-ups in the Jacob van Lennep neighbourhood have a shared staircase, residents in these houses share communal spaces with far fewer other residents and in a less anonymous setting than residents in the large modern housing blocks in the Harbour Island West neighbourhood. These differences in architectural design seem to have an important impact on everyday contact between neighbours. In this study, residents were interviewed in a survey about their everyday use of semi-public spaces, such as corridors, staircases and lifts and how they interact with each other in these places and in the neighbourhood. The survey included seven questions about irritations that could potentially arise from everyday contact and interaction in these places, whereby residents had to respond to statements such as "other neighbourhood residents do not correct their children if they are a nuisance to people in the streets," "neighbourhood residents have different norms and values regarding what is acceptable in the neighbourhood," or "neighbourhood residents have conflicts about keeping hallways or corridors clean." The outcomes in the New Harbour West neighbourhood for all seven questions show a significant relation with experienced tensions (all at the level of $p<0.01$; Broekhuizen et al., 2012, p. 83). The comparison of the New Harbour West neighbourhood with the Jacob van Lennep neighbourhood is remarkable, since in the latter neighbourhood only one out of the seven statements about the use of semi-public spaces and the interaction between residents was significantly related to tensions experienced in the neighbourhood. This correlation $(p<0.05)$ is weak and was found for only one item: "Putting the garbage outside at the wrong time" (Wonderen \& Broekhuizen, 2012, p. 93).

The qualitative part of this study hints at further explanations for the large differences between the two neighbourhoods. Young children (under age twelve) playing in the inner courtyards in the Harbour Island West neighbourhood are one of the main causes of perceived conflicts. Both residents and professionals interviewed report this. The inner courtyards amplify the sound of playing children, resulting in many complaints about noise (Broekhuizen et al., 2012, p. 69). Normal behaviour for young children at play was causing a nuisance for residents because of the architectural design of the housing. The housing blocks were accommodating relatively more young children than the designers of the buildings had foreseen. The second perceived nuisance was caused by teenagers, mostly boys, hanging out in corridors and hallways (Broekhuizen et al., 2012, p. 68). These teenagers are mostly of Moroccan, Antillean and Surinamese descent, which are the three largest groups in this age group. They were gathering in hallways and corridors as this relatively new neighbourhood had no other facilities where they could meet and is relatively far away from the city centre. On top of this, the rainy Dutch climate makes protected shelters a must. The Jacob van Lennep neighbourhood has no inner courtyards where children can play, and residents do not share an entrance to massive housing blocks. There are no hallways where teenage youths can 'hang out.' The design of housing blocks here limits the amount of involuntary contact between residents. Not only are everyday interactions in the two neighbourhoods different, respondents in the Harbour Island West neighbourhood also frame these conflicts through an ethnic lens more often, by accusing certain ethnic groups of 'misbehaviour.' More than a third $(37 \%)$ of the respondents in the Harbour Island West neighbourhood pointed to specific ethnic groups that they thought were causing problems (Broekhuizen et al., 2012, p. 28).

Not only were there differences in the perception of experienced tensions, there were also differences with regard to contact. Residents of the Jacob van Lennep 
neighbourhood mention having significantly more frequent interethnic contacts. These contacts correlate with feeling safe and comfortable in this neighbourhood and seem to result in a generally positive climate: if negative experiences occur (and, of course, they also occur in this neighbourhood) they are less often labelled as being ethnically driven (Paolini et al., 2014). The balance between more positive and fewer negative interethnic contacts might prevent people from putting an ethnic label on incidents. In the Harbour Island West neighbourhood, on the other hand, some residents of Dutch descent were confronted with the very people they had tried to avoid at an earlier stage of their housing career by leaving their ethnically diverse neighbourhood. As Harbour Island West residents have more involuntary contact due to the architecture of this neighbourhood, the potential for tensions seems plentiful and tensions do indeed escalate (Árnadóttir et al., 2018; Barlow et al., 2012).

An important caveat for the Harbour Island West neighbourhood is that it is a new neighbourhood that all residents moved to at more or less the same time. This may have amplified differences because new residents have not moved in gradually as would have been the case in a more established neighbourhood. This, however, makes it a good case study, as under such circumstances it might be easier to identify which housing arrangements have the potential to turn minor tensions into conflicts.

\section{Dampening or Amplifying Ethnic Tensions}

In the previous section we demonstrated that there are significant differences between different types of neighbourhoods with regard to the number of residents with either negative or positive attitudes towards ethnic diversity. In the inner-city neighbourhoods, the people who see diversity as something that enriches their lives far outnumber those who consider it as a threat. In some suburban neighbourhoods, such as the Harbour Island West neighbourhood, the balance is different. More people there stated that they perceive diversity as threatening. Here, the fact that a number of residents had already formed negative opinions about living in a diverse setting at an earlier stage of their life makes it more probable that they now interpret interethnic interactions is a more negative manner. The architectural context that forces residents to share and, in some occasions, compete for the many semi-public spaces may amplify these negative feelings. In this final section we will try to add another piece to the puzzle of how and why interethnic contact results in tensions labelled as interethnic tensions-or not. Whether the discourse about interethnic tensions in the neighbourhood is spread and negative attitudes are amplified or, on the contrary, dampened also seems to depend on the way in which people with more positive or more negative attitudes towards diversity influence the climate in a neighbourhood. We looked into the rate of active participation in organizations among people who perceive diversity as a threat on the one hand and among those who think it is enriching on the other. The idea behind this is that both negative and positive attitudes towards diversity will probably be discussed with others in formal and informal conversations within these organizations. People with positive attitudes may dampen ethnically framed conflicts while people with negative attitudes may fuel them while spreading their ideas (see Crul \& Lelie, 2017). Once more, we will make use of the TIES survey to analyse this piece of the puzzle.

First, we examined whether there was any difference between people with more positive and more negative attitudes towards ethnic diversity when it comes to participating in social, cultural, housing, trade union, sports and other organizations, which is reflected in Table 2. It turns out that there is a correlation $(p<0.01)$. People who stated that ethnic diversity is enriching participated in such organizations much more often. People with negative opinions were far less active in organizations. This means they have far fewer encounters with other people in organizations that could serve as a platform for their negative opinions.

One should of course be careful to generalize these findings by saying that negative opinions have much less traction in a neighbourhood setting than within an organization. Informal discussions on the street between neighbours, in shops or at the playground could be the places where people with negative attitudes vent their opinions. We have no information on the frequency of this type of interaction.

The frequency of participation in organizations is also strongly linked to a person's educational level. Residents

Table 2. People of Dutch descent between 18 and 35 years of age in Amsterdam neighbourhoods: Being active in organizations and their attitude towards ethnic diversity.

\begin{tabular}{lcc}
\hline $\begin{array}{l}\text { "Living together with people of different ethnic } \\
\text { origin is an enrichment or a threat?" }\end{array}$ & $\begin{array}{c}\text { Residents active } \\
\text { in organizations }\end{array}$ & $\begin{array}{c}\text { Residents not active } \\
\text { in organizations }\end{array}$ \\
\hline Threatening & $50 \%$ & $50 \%$ \\
Rather threatening & $42 \%$ & $58 \%$ \\
Makes no difference & $77 \%$ & $23 \%$ \\
Rather Enriching & $86 \%$ & $14 \%$ \\
Enriching & $78 \%$ & $22 \%$ \\
\hline
\end{tabular}

Source: TIES Survey (2008). 
with a higher level of education participate in organizations more often. This is especially true for institutional organizations at the neighbourhood level, such as neighbourhood, housing and other social organizations (which are sometimes set up to promote contact between different residents in a neighbourhood). Higher-educated people living in lower-class neighbourhoods often play an important role in such organizations. This needs further research that our survey cannot provide. But we think that our findings point to an important piece of the puzzle regarding why tensions have built up to such an extent in the Harbour Island West neighbourhood. This neighbourhood was designed to mix people from different social backgrounds. Some of the residents responsible for exacerbating tensions were home-owners living in housing blocks that also contained rented social housing. Some of the residents who reported negative feelings about living in an ethnically diverse neighbourhood belonged to the higher-educated middle class. They were active in the neighbourhood and housing associations more often than residents from a lower-class background and this gave them a platform from which they could influence the climate within these organizations and raise ethnic tensions (see Broekhuizen et al., 2012, pp. 68-72). Ethnic tensions were not only experienced and played out between neighbours, but also became a topic at the institutional level of housing corporations and neighbourhood organizations and even the police. As one of the neighbourhood's professionals notes, these residents were quick to call in professionals as their natural allies, saying: "They even call the police when a three year-old riding his tricycle is making noise in the courtyard, because they want to drink their rosé on their balcony in peace" (Broekhuizen et al., 2012, p. 70).

\section{Conclusion}

The data points to residents of inner-city working-class neighbourhoods being less negative about ethnic diversity than their counterparts in suburban working-class neighbourhoods and that architecture plays an important role in this. People in inner-city working-class neighbourhoods share fewer semi-public spaces, such as galleries, inner courtyards, garages and lifts. This means that there is less unavoidable contact with other residents, and that contact, including interethnic contact between neighbours, takes place on a more voluntary basis. We also saw that suburban working-class neighbourhoods were more often home to residents with previous experience of living in ethnically diverse settings. Drawing on the work of social psychologists we suggest that previous interethnic contacts-both positive and negative-and their effects over time are another piece of the puzzle of why different types of neighbourhoods demonstrate an amplification or dampening of perceived ethnic tensions. However, to substantiate this, one would need a longitudinal research design. People with either positive or negative attitudes towards ethnic diversity are likely to affect the climate in a neighbourhood, both through their interactions with other residents and through the organizations they actively participate in. More crucially, participation in social organizations such as neighbourhood and community organizations can bring conflicts and tensions to an institutional level. Ethnic tensions can run high, as was the case in the New Harbour West neighbourhood, due to a cocktail of these mechanisms, circumstances and dynamics. In this case, some of the residents who moved to this neighbourhood had already developed negative attitudes towards ethnic diversity. The fact that the neighbourhood's architecture forced them to share, and sometimes compete for, semi-public spaces with residents from other ethnic backgrounds intensified these feelings. These tensions reached the institutional level as a number of these residents were vocal in neighbourhood organizations. Our article suggests that many conditions must coincide in order for interethnic conflicts to escalate to the point described in this particular neighbourhood. In general, our findings suggest that the balance leans towards a positive reception of ethnic diversity (based on positive contact, both in the past and the present) and that there are many checks in place to dampen any potential ethnic tensions. In all twenty-three Amsterdam neighbourhoods surveyed, those stating that ethnic diversity is an enrichment form the largest group, and since these people are also more active in social organizations, they will potentially influence the discourse on ethnic diversity at the institutional level in a positive direction and dampen negative attitudes.

Theoretically our findings show that in order to study ethnic tensions, we need an interdisciplinary framework that looks at both the individual and the group level and takes into consideration both institutional factors like the architecture of housing blocks and neighbourhoods and the effect of participation in social organizations. In practice this means intertwining the study of human and physical conditions. We propose that institutional conditions such as the architecture of housing and neighbourhoods and participation in social organizations are fruitful avenues for further quantitative and qualitative research.

\section{Acknowledgments}

The article reflects part of the secondary data analysis for the project Becoming a Minority (BAM), which was awarded with ERC Advanced Grant No. 741532. The authors want to thank the anonymous reviewers for their helpful comments. They also want to thank Liz Cross for her careful proofreading.

\section{Conflict of Interests}

The authors declare no conflict of interests. 


\section{References}

Allport, G. (1954). The nature of prejudice. Cambridge: Perseus Books.

Amir, Y. (1976). The role of intergroup contact in the change of prejudice and ethnic relations. In P. A. Katz (Ed.), Towards the elimination of racism. New York, NY: Pergamon.

Árnadóttir, K., Lolliot, S., Brown, R., \& Hewstone, M. (2018). Positive and negative intergroup contact: Interaction not asymmetry. European Journal of Social Psychology, 48(6), 784-800.

Barlow, F., Paolini, S., Pedersen, A., Hornsey, M., Radke, H., Harwood, J., . . . Sibley, C. (2012). The contact caveat: Negative contact predicts increased prejudice more than positive contact predicts reduced prejudice. Personality and Social Psychology Bulletin, 38(12), 1629-1642.

Brewer, M., \& Kramer, R. (1985). The psychology of intergroup attitudes and behaviour. Annual Review of Psychology, 36(1), 219-243.

Broekhuizen, J., van Marissing, E., \& Wonderen, R. (2012). Samenleven met verschillen in Oost [Living together with differences in Amsterdam East]. Amsterdam: Verwey Jonker Instituut \& Bureau Onderzoek en Statistiek.

Brubaker, R., \& Laitan, D. (2004). Ethnic and nationalist violence. In R. Brubaker (Ed.), Ethnicity without groups. Cambridge, MA: Harvard University Press.

Statistics Netherlands. (2020). Begrippen [Definitions]. Centraal Bureau voor de Statistiek. Retrieved from https://www.cbs.nl/nl-nl/onze-diensten/methoden/ begrippen?tab=p\#id=persoon-met-een-nederlandse -achtergrond Retrieved on 24-2-2020

Crul, M., \& Heering, L. (Eds.). (2008). The position of the Turkish and Moroccan second generation in Amsterdam and Rotterdam: The TIES study in the Netherlands. Amsterdam: Amsterdam University Press.

Crul, M., \& Lelie, F. (2017). De integratie van mensen van Nederlandse afkomst in superdiverse wijken [The integration of people of Dutch descent in superdiverse neighborhoods]. Tijdschrift over cultuur en criminaliteit, 7(1), 39-57.

Groenewold, G. (2008). Sample design. TIES survey implementation and evaluation. In M. Crul \& L. Heering (Eds.), The position of the Turkish and Moroc- can second generation in Amsterdam and Rotterdam: The TIES study in the Netherlands (Appendix). Amsterdam: Amsterdam University Press.

Horowitz, D. (1985). Ethnic groups in conflict. Berkeley, CA: University of California Press.

Paolini, S., Harwood, J., Rubin, M., Husnu, S., Joyce, N., \& Hewstone, M. (2014). Positive and extensive intergroup contact in the past buffers against the disproportionate impact of negative contact in the present. European Journal of Social Psychology, 44(6), 548-562.

Pettigrew, T. (1998). Intergroup contact theory. Annual Review of Psychology, 49(1), 65-85.

Pettigrew, T., \& Tropp, L. (2006). A meta-analytic test of intergroup contact theory. Journal of Personality and Social Psychology, 90(5), 751-783.

Rothbart, J., \& John, O. (1985). Social categorization and behavioural episodes: A cognitive analysis of the effects of intergroup contact. Journal of Social Issues, 41, 81-104.

Tersteeg, A., \& Pinkster, F. (2016). “Us up here and them down there": How design, management, and neighborhood facilities shape social distance in a mixedtenure housing development. Urban Affairs Review, 52(5), 751-779.

TIES Survey. (2008). The Integration of the European second generation in Amsterdam and Rotterdam (TIES$\mathrm{NL}$ ). DANS. Retrieved from https://easy.dans.knaw. $\mathrm{nl} /$ ui/datasets/id/easy-dataset:34349

Tropp, L. (2016). Memo on intergroup contact in contexts of conflict for israel under the shadow of conflict: $A$ reappraisal of current processes and of future repercussions (Advanced Research Collaborative Report). New York, NY: Graduate Center of the City University of New York.

van Marissing, E. (2014). Overlast en criminaliteit op IJburg [Disturbance and criminality in the IJburg neighbourhood]. Utrecht: Verwey Jonker Institute.

Wonderen, J., \& Broekhuizen, J. (2012). Samenleven met verschillen in West [Living together with differences in Amsterdam West]. Amsterdam: Verwey Jonker Instituut \& Bureau Onderzoek en Statistiek.

Wright, S., Aron, A., Mc Laughlin-Volpe, T., \& Ropp, S. (1997). The extended contact effect: Knowledge of cross group friendships and prejudice. Journal of Personality Social Psychology, 73(1), 73-90.

\section{About the Authors}

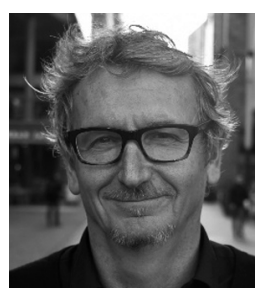

Maurice Crul is a Professor of Sociology at the Vrije Universiteit in Amsterdam. In the past twenty-five years he has mostly worked on the topic of education and the children of immigrants, first within the Dutch context and during the last twenty years in a comparative European and transatlantic context. Maurice Crul has coordinated two major international projects: the TIES project and the ELITES project. In 2017 he was awarded the ERC Advanced Grant for Becoming a Minority (BaM), a project to study the integration of people of native descent in majority-minority cities in Europe. 


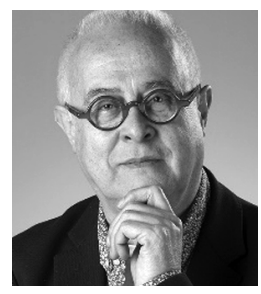

Carl H. D. Steinmetz was born in Indonesia. He is a Psychologist and a Victimologist. He was one of the co-founders of the national organization Slachtofferhulp Nederland (Victim Support the Netherlands) and worked in Canada in community prevention. He is the Managing Director of Expats \& Immigrants. His fields of expertise are workplace violence, transcultural psychology, and the implications of superdiversity for the educational, labour and healthcare systems. He promotes cultural awareness and sensitivity in the workplace and is working on radicalization and terrorism. Carl Steinmetz has also set up projects working with extended families in schools in the highly-diverse borough of Amsterdam Nieuw-West.

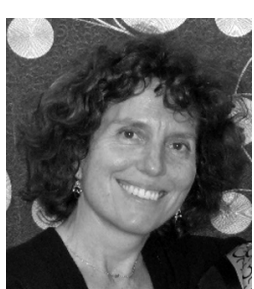

Frans Lelie is a Fellow at the Department of Sociology at the Vrije Universiteit in Amsterdam. A social worker by training, she worked extensively with women and their families with a migration background. In the last fifteen years she has worked on the topic of education and the children of immigrants in two major international projects: TIES and ELITES, Pathways to Success. Frans is currently part of the ERC project Becoming a Minority (BaM) on the integration of people of native descent in majority-minority cities in Europe. 